\title{
Growth hormone-releasing hormone (GHRH) polymorphisms associated with carcass traits of meat in Korean cattle Hyun Sub Cheong ${ }^{1}$, Du-Hak Yoon ${ }^{2}$, Lyoung Hyo Kim ${ }^{1}$, Byung Lae Park ${ }^{1}$, Yoo Hyun Choi ${ }^{1}$, Eui Ryong Chung 3 , Yong Min Cho², Eng Woo Park², Il- Cheong Cheong ${ }^{2}$, Sung-Jong $\mathrm{Oh}^{2}$, Sung-Gon $\mathrm{Yi}^{4}$, Taesung Park ${ }^{4}$ and Hyoung Doo Shin*1
}

\begin{abstract}
Address: ${ }^{1}$ Department of Genetic Epidemiology, SNP Genetics, Inc., Seoul, 153-803, Korea, ${ }^{2}$ National Livestock Research Institute, RDA, 441-706 Korea, ${ }^{3}$ Department of Biotechnology, Sangi University, Wonju, Kangwon Do, 220-702, Korea and ${ }^{4}$ Department of Statistics, Seoul National University, Seoul, 151-747, Korea

Email: Hyun Sub Cheong - chhs@snp-genetics.com; Du-Hak Yoon - dhyoon@rda.go.kr; Lyoung Hyo Kim - lyoung@snp-genetics.com; Byung Lae Park - blpark@snp-genetics.com; Yoo Hyun Choi - uhyunni@snp-genetics.com; Eui Ryong Chung - erchung@sangji.ac.kr; Yong Min Cho - variance@rda.go.kr; Eng Woo Park - pewkys@rda.go.kr; Il-Cheong Cheong - cheongic@rda.go.kr; SungJong Oh - ohsj@rda.go.kr; Sung-Gon Yi - skon@kr.FreeBSD.org; Taesung Park - tspark@snu.ac.kr; Hyoung Doo Shin* - hdshin@snpgenetics.com

* Corresponding author
\end{abstract}

Published: 03 June 2006

BMC Genetics 2006, 7:35 doi:10.1/86/147/-2156-7-35
Received: 0I November 2005

Accepted: 03 June 2006

This article is available from: http://www.biomedcentral.com/I47/-2/56/7/35

(c) 2006 Cheong et al; licensee BioMed Central Ltd.

This is an Open Access article distributed under the terms of the Creative Commons Attribution License (http://creativecommons.org/licenses/by/2.0), which permits unrestricted use, distribution, and reproduction in any medium, provided the original work is properly cited.

\begin{abstract}
Background: Cold carcass weight (CW) and longissimus muscle area (EMA) are the major quantitative traits in beef cattle. In this study, we found several polymorphisms of growth hormonereleasing hormone $(\mathrm{GHRH})$ gene and examined the association of polymorphisms with carcass traits (CW and EMA) in Korean native cattle (Hanwoo).

Results: By direct DNA sequencing in 24 unrelated Korean cattle, we identified 12 single nucleotide polymorphisms within the $9 \mathrm{~kb}$ full gene region, including the $1.5 \mathrm{~kb}$ promoter region. Among them, six polymorphic sites were selected for genotyping in our beef cattle $(n=428)$ and five marker haplotypes (frequency $>0.1$ ) were identified. Statistical analysis revealed that $-424 I A>T$ showed significant associations with CW and EMA.

Conclusion: Our findings suggest that polymorphisms in GHRH might be one of the important genetic factors that influence carcass yield in beef cattle. Sequence variation/haplotype information identified in this study would provide valuable information for the production of a commercial line of beef cattle.
\end{abstract}

\section{Background}

The successful application of marker-assisted selection in the commercial animal population will depend on the identification of genes, including identification of genes underlying quantitative traits, exploration of genetic pol- ymorphisms that are involved in different phenotypes of quantitative traits, and understanding how these genes/ polymorphisms interact with the environment or with other genes affecting economic traits. 
The growth hormone $(\mathrm{GH})$ is essential for post-natal growth and general metabolism, and also plays an important role in lactation. Current knowledge indicates that GH exerts a key influence in nutrient use [1], mammary development [2], and growth [3]. There have been several reports of association between quantitative traits in cattle, such as growth performance and carcass merit, and polymorphisms in the GH gene [4-6].

The regulation of GH synthesis and secretion is multifactorial, but the predominant regulators of $\mathrm{GH}$ are the hypothalamic hormones, GH-releasing hormone (GHRH), GH secretagogue (GHS), and somatostatin (SS) [7]. In spite of the functional importance of GHRH in the regulation of $\mathrm{GH}$, only one PCR-restriction fragmentlength polymorphism (RFLP) [8] has been reported in cattle.

In this study, we examined GHRH as one of candidate genes in meat production. We performed extensive screening of GHRH by direct sequencing to detect polymorphisms and examined genetic association with the carcass traits. Here, we present 12 polymorphisms identified in GHRH and the results of an association study with meat quantity in Korean native cattle (Hanwoo).

\section{Results and discussion}

By direct DNA sequencing, 12 polymorphisms were identified in GHRH: one in 5'UTR and 11 in introns. The locations and allele frequencies of polymorphism are shown in Table 1 and Figure 1. By pair-wise linkage analysis with DNA from the 24 unrelated Korean cattle, which were used for direct sequencing, we have found that two sets of polymorphisms were in absolute LDs $\left(\left|\mathrm{D}^{\prime}\right|=1\right.$ and $\left.r^{2}=1\right)$. Several sets of polymorphisms in complete LDs $\left(\left|\mathrm{D}^{\prime}\right|=1\right.$ and $r^{2} \neq 1$ ) were also identified (Figure 1 and Table 2).

Among identified polymorphisms, six SNPs (-4241A $>$ T, $3195 \mathrm{~T}>\mathrm{A}, \quad-618 \mathrm{~T}>\mathrm{A}, \quad+114 \mathrm{C}>\mathrm{A}, \quad+2042 \mathrm{~A}>\mathrm{G}$ and $+2279 \mathrm{C}>\mathrm{T}$ ) were selected for larger-scale genotyping based on LDs (only one polymorphism if there are absolute LDs $(\mathrm{r} 2=1)$ ) and frequencies $(>0.1)$. Five major haplotypes (freq. $>0.1$ ) were constructed (Table 3 ). Minor allele frequencies of SNP are shown in Table 1.

Associations of GHRH polymorphisms with carcass traits were analyzed using the mixed effect model with sire and age as covariates. Sire was treated as a random effect and age a fixed effect. The obtained $P$ values were corrected for multiple testing by the effective number of independent marker loci (5.35) in GHRH. In addition, the permutation tests were performed for adjusting $\mathrm{P}$ values and for controlling the false discovery rate (FDR). Among five common haplotypes (freq. > 0.1) identified, $h t 3$ was not used for further analysis because it was almost completely (>
$93 \%$ ) tagged by a single SNP, $+2042 A>G$ (Table 3). Haplotypes $(h t 6-h t 9)$ with frequencies less than 0.1 were not analyzed either.

By statistical analyses, $-4241 \mathrm{~A}>\mathrm{T}$ showed significant associations with cold carcass weight (CW) and longissimus muscle area (EMA) and the genetic effects of $-4241 A>T$ were in gene dose dependent manner. CW and EMA were highest in " $\mathrm{T}$ " allele homozygotes $(\mathrm{CW}=321.7 \pm 36.4$ and $\mathrm{EMA}=78.2 \pm 9.3)$, intermediate in "A/T" heterozygotes $(\mathrm{CW}=315.3 \pm 33.1$ and $\mathrm{EMA}=75.7 \pm 8.7)$, and lowest in "A" allele homozygotes $(\mathrm{CW}=306.2 \pm 32.5$ and $\mathrm{EMA}=$ $74.1 \pm 8.2)(P C O R=0.025$ and 0.046 for CW and EMA, respectively). The simple corrected $P C O R$ and the permutation based $P^{W Y}$ provided consistent results, though there were some slight differences. The $Q^{S A M}$ represents the FDR value showing the consistent results. Similar mixed model was fit for the haplotype association analysis. However, none of the haplotypes were found to be significantly associated with CW and EMA (Table 4).

Linear growth in vertebrate organisms is highly dependent on the GH [9]. GH is a lipolytic hormone, activating lipase and thereby mobilizing fat from adipose tissue [10]. While the primary action of GH is to stimulate skeletal and visceral growth, it has important metabolic actions as well. As a consequence of these actions, deficiency of GH can result in lowered growth rate [11], delayed bone maturation [12], decreased body mass [13], and hypoglycemia [14].

In a recent study, a GHRH polymorphism (AluI) was associated with yield traits (the average daily gain and expected progeny difference for fat thickness) in landrace pigs [15]. In this study, we also found that polymorphisms in GHRH, one of the predominant regulators of GH releasing [16], were associated with carcass yield traits (CW and EMA) in Korean native cattle.

Although the mechanisms involved in the association of alternative genotypes in the UTR and intronic SNPs with CW and EMA are not currently understood, the crucial role of the non-coding portion of genomes is now widely acknowledged. Polymorphisms within introns can affect gene function by affecting both the splice donor or acceptor site or regions nearby and regulatory motifs within introns. And UTRs are involved in many post-transciptional regulatory pathways that control mRNA localisation, stability, translation efficiency and initiation of protein synthesis. The post-transcriptional events play an important, yet incompletely understood, role in regulatory gene expression and cellular behaviour; many of the identified cis-acting elements for translational regulation occur within the UTR [17]. 
Table I: Genotype and allele frequencies of 12 polymorphisms detected in GHRH

\begin{tabular}{|c|c|c|c|c|c|c|c|c|}
\hline \multirow{2}{*}{$\begin{array}{c}\text { Name } \\
-424 \mid A>T\end{array}$} & \multirow{2}{*}{$\begin{array}{l}\text { Region } \\
\text { 5'UTR }\end{array}$} & \multicolumn{4}{|c|}{ Genotype } & \multirow{2}{*}{$\begin{array}{c}\begin{array}{c}\text { Minor allele } \\
\text { frequency }\end{array} \\
0.290\end{array}$} & \multirow{2}{*}{$\begin{array}{c}\text { Heterozygosit } \\
y\end{array}$} & \multirow{2}{*}{$\begin{array}{l}\text { HWE* } \\
0.903\end{array}$} \\
\hline & & AA & AT & $\mathrm{TT}$ & $N$ & & & \\
\hline & & $214 \$$ & 180 & 34 & 428 & & & \\
\hline \multirow[t]{2}{*}{$-4 \mid 44 G>A$} & Intron I & GG & AG & AA & $N$ & 0.091 & 0.165 & 0.896 \\
\hline & & 18 & 4 & 0 & 22 & & & \\
\hline \multirow[t]{2}{*}{$-3 / 95 T>A$} & Intron I & TT & AT & AA & $N$ & 0.409 & 0.484 & 0.255 \\
\hline & & 140 & 222 & 63 & 425 & & & \\
\hline \multirow[t]{2}{*}{$-2846 C>T$} & Intron I & $\mathrm{CC}$ & $\mathrm{CT}$ & $\mathrm{TT}$ & $N$ & 0.021 & 0.041 & 0.995 \\
\hline & & 23 & 1 & 0 & 24 & & & \\
\hline \multirow[t]{2}{*}{$-2298 A>C$} & Intron I & AA & $A C$ & $\mathrm{CC}$ & $N$ & 0.300 & 0.420 & 0.159 \\
\hline & & 8 & 12 & 0 & 20 & & & \\
\hline \multirow[t]{2}{*}{$-6 \mid 8 T>A$} & Intron I & TT & AT & AA & $N$ & 0.278 & 0.401 & 0.365 \\
\hline & & 217 & 183 & 27 & 427 & & & \\
\hline \multirow[t]{2}{*}{$+1 \mid 4 C>A$} & Intron2 & $\mathrm{CC}$ & $A C$ & AA & $N$ & 0.311 & 0.429 & 0.894 \\
\hline & & 199 & 186 & 39 & 424 & & & \\
\hline \multirow[t]{2}{*}{$+2042 A>G$} & Intron3 & $A A$ & AG & GG & $N$ & 0.193 & 0.311 & 0.968 \\
\hline & & 276 & 134 & 15 & 425 & & & \\
\hline \multirow[t]{2}{*}{$+2279 C>T$} & Intron3 & $\mathrm{CC}$ & $\mathrm{CT}$ & $\mathrm{TT}$ & $N$ & 0.299 & 0.419 & 0.792 \\
\hline & & 206 & 184 & 35 & 425 & & & \\
\hline \multirow[t]{2}{*}{$+2555 G>A$} & Intron3 & GG & AG & AA & $N$ & 0.250 & 0.375 & 0.777 \\
\hline & & 13 & 7 & 2 & 22 & & & \\
\hline \multirow[t]{2}{*}{$+3744 G>A$} & Intron4 & GG & AG & AA & $N$ & 0.043 & 0.083 & 0.977 \\
\hline & & 21 & 2 & 0 & 23 & & & \\
\hline \multirow[t]{2}{*}{$+4522 T>C$} & Intron4 & TT & CT & $\mathrm{CC}$ & $\mathrm{N}$ & 0.021 & $0.04 I$ & 0.995 \\
\hline & & 23 & I & 0 & 24 & & & \\
\hline
\end{tabular}

* $P$ value for deviation of genotype distribution from Hardy-Weinberg equilibrium (HWE)

$\$$ number of animals with that particular genotype

\section{Conclusion}

We have identified 12 polymorphisms in GHRH, and six polymorphic sites were selected for genotyping in Korean native cattle. Statistical analysis revealed that GHRH $4241 A>T$ showed significant association with carcass traits. Replication of our finding in an independent dataset and/or functional validation of polymorphisms should be performed in the future.

\section{Methods}

\section{Animals and phenotypic data}

The Korean native cattle genomic DNA samples were obtained from 428 steers produced from 76 sires used in progeny testing program of National Livestock Research Institute (NLRI) of Korea. The dams were inseminated randomly with young sires. All steers were fed for 731.39 \pm 16.53 days period under tightly controlled feeding program in Daekwanryeong and Namwon branch of NLRI. Live weights were determined before slaughter. Mean of live weights was $539.93 \pm 51.96 \mathrm{~kg}$. Yield grades for carcasses were determined by CW and EMA. After a 24-h chill, CW was measured, and then the left side of each carcass was cut between the last rib and the first lumbar vertebrae to determine EMA. EMA was determined at the surface using a grid [18]. Means of carcass traits were $311.47 \pm 33.39 \mathrm{~kg}(\mathrm{CW})$ and $75.16 \pm 8.62 \mathrm{~cm}^{2}(\mathrm{EMA})$. 


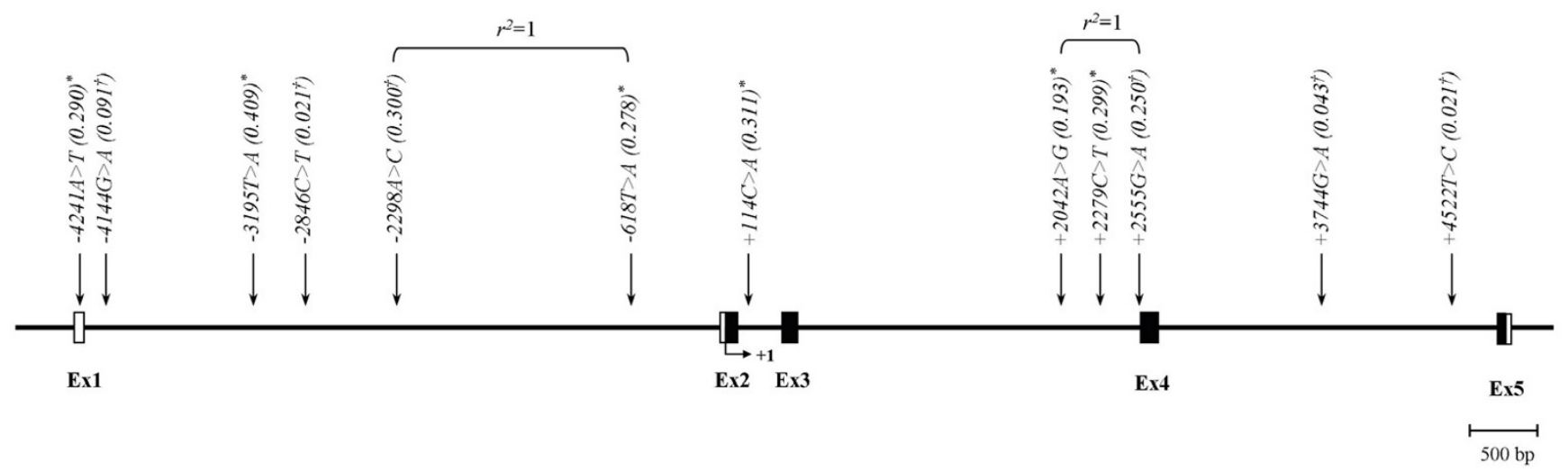

Figure I

Map of SNPs in GHRH on chromosome 13. The exons are marked by black block, and 5' and 3' UTRs indicated by open blocks. First base of translational site is denoted as nucleotide + I. Asterisks $\left(^{*}\right)$ indicate polymorphisms genotyped in a larger Korean cattle $(n=428)$. tThe minor allele frequency based on 24 sequencing samples only, which is different with minor allele frequency of absolutely linked SNP genotyped in larger population.

\section{Sequencing analysis of GHRH}

We have sequenced the $9 \mathrm{~kb}$ full genome, including the promoter region $(1.5 \mathrm{~kb})$, to discover variants in 24 unrelated Korean native cattle using the ABI PRISM 3730 DNA analyzer (Applied Biosystems, Foster City, CA). Nineteen primer sets for the amplification and sequencing analysis were designed based on GenBank sequences (Ref. Genome seq.; AF242855 released on July 30, 2000). Primer information is available on website [19]. Sequence variants were verified by chromatograms.

\section{Genotyping by single-base extension (SBE) and electrophoresis}

For genotyping of polymorphic sites, amplifying and extension primers were designed for single-base extension (SBE) [20]. Primer extension reactions were performed with the SNaPshot ddNTP Primer Extension Kit (Applied Biosystems). To clean up the primer extension reaction, one unit of SAP (shrimp alkaline phosphatase) was added to the reaction mixture, and the mixture was incubated at $37^{\circ} \mathrm{C}$ for 1 hour, followed by $15 \mathrm{~min}$ at $72^{\circ} \mathrm{C}$ for enzyme inactivation. The DNA samples, containing extension products, and Genescan 120 Liz size standard solution was added to Hi-Di formamide (Applied Biosystems) according to the recommendations of the manufacturer. The mixture was incubated at $95^{\circ} \mathrm{C}$ for $5 \mathrm{~min}$, followed by 5 min on ice, and then electrophoresis was performed using the ABI Prism 3100 Genetic Analyzer. The results were analyzed using the program of ABI Prism GeneScan and Genotyper (Applied Biosystems). Probe information is available on website [19].

\section{Statistics}

The $\mathrm{X}^{2}$ tests were used to determine whether individual variants were in equilibrium at each locus in the population (Hardy-Weinberg equilibrium). We examined a widely used measure of linkage disequilibrium between all pairs of biallelic loci, Lewontin's D' (|D'|) [21], and $r^{2}$. Haplotypes and their frequencies were inferred using the algorithm developed by Stephens et al [22]. Phase probabilities of each site were calculated for each individual using this software. Association analyses with carcass traits (CW and EMA) were performed using a mixed effect model treating "sire" as a random effect. Age at slaughter

Table 2: Linkage disequilibrium coefficient (|D'| and $\left.r^{2}\right)$ among GHRH SNPs

\begin{tabular}{|c|c|c|c|c|c|c|c|}
\hline & \multicolumn{7}{|c|}{$\left|D^{\prime}\right|$} \\
\hline & SNPs & $-424 I A>T$ & $-3 / 95 T>A$ & $-6 / 8 T>A$ & $+114 C>A$ & $+2042 A>G$ & $+2279 C>T$ \\
\hline \multirow[t]{6}{*}{$r^{2}$} & $-424 \mid A>T$ & - & 0.550 & 0.121 & 0.935 & 0.835 & 0.129 \\
\hline & $-3 / 95 T>A$ & 0.175 & - & 0.928 & 1.000 & 0.748 & 0.545 \\
\hline & $-6 / 8 T>A$ & 0.002 & 0.232 & - & 1.000 & 0.533 & 0.181 \\
\hline & $+114 C>A$ & 0.160 & 0.317 & 0.174 & - & 0.941 & 0.126 \\
\hline & $+2042 A>G$ & 0.404 & 0.187 & 0.026 & 0.094 & - & 1.000 \\
\hline & $+2279 C>T$ & 0.016 & 0.089 & 0.029 & 0.015 & 0.100 & - \\
\hline
\end{tabular}


Table 3: Haplotypes and frequencies of GHRH among Korean native cattle.

\begin{tabular}{|c|c|c|c|c|c|c|c|}
\hline Haplotype & $-424 I A>T$ & $-3 / 95 T>A$ & $-6 / 8 T>A$ & $+1 \mid 4 C>A$ & $+2042 A>G$ & $+2279 C>T$ & Frequency \\
\hline$h t l$ & A & $\mathrm{T}$ & $\mathrm{T}$ & A & A & C & 0.189 \\
\hline$h t 2$ & $A$ & $A$ & $T$ & C & $A$ & $\mathrm{C}$ & 0.183 \\
\hline$h t 3$ & $\mathrm{~T}$ & $A$ & $\mathrm{~T}$ & C & G & C & 0.162 \\
\hline ht4 & A & $\mathrm{T}$ & A & C & A & C & 0.122 \\
\hline$h t 5$ & $A$ & $\mathrm{~T}$ & $\mathrm{~T}$ & $A$ & $A$ & $\mathrm{~T}$ & 0.114 \\
\hline ht6 & $\mathrm{T}$ & $\mathrm{T}$ & $A$ & C & A & $\mathrm{T}$ & 0.060 \\
\hline ht7 & $A$ & $\mathrm{~T}$ & $A$ & C & $A$ & $\mathrm{~T}$ & 0.059 \\
\hline ht8 & $\mathrm{T}$ & A & $\mathrm{T}$ & C & $A$ & $\mathrm{~T}$ & 0.047 \\
\hline ht9 & $A$ & $\mathrm{~T}$ & A & C & G & C & 0.019 \\
\hline Others* & . & . & . & . & . & . & 0.048 \\
\hline
\end{tabular}

*Others contain rare haplotypes: AATCAT, AAACAC, TTTAAT, TTACGC, ATTCAT and TTACAC.

was also included in the model. Other covariates were not available for this analysis. We fit a full model that includes all six SNPs in the model. We think the full model is more appropriate for controlling the closely linked SNPs more effectively. The effective number of independent marker loci in GHRH was calculated to correct for multiple testing. The effective number in GHRH was calculated using the software SNPSpD [23], which is based on the spectral decomposition (SpD) of matrices of pair-wise LD between SNPs. The resulting number of independent marker loci was applied to correct for multiple testing [24]. In addition, we performed the permutation test by controlling the $\mathrm{P}$ values by the Westfall and Young's method [25] and by controlling the FDR [26]. For the haplotype analyses, we fit the model including four haplotypes with the same covariates and performed the permutation test in a similar manner.

Table 4: Association analyses of the GHRH polymorphisms with carcass traits (CW and EMA) among Korean native cattle

\begin{tabular}{|c|c|c|c|c|c|c|c|c|c|}
\hline \multirow[t]{2}{*}{ Trait } & \multirow[t]{2}{*}{ Loci } & \multirow[t]{2}{*}{ Location } & \multicolumn{3}{|c|}{ Genotype } & \multirow[t]{2}{*}{$P$} & \multirow[t]{2}{*}{ PCOR } & \multirow[t]{2}{*}{ PWY } & \multirow[t]{2}{*}{$Q^{S A M}$} \\
\hline & & & $\mathrm{C} / \mathrm{C}^{*}$ & $C / R^{*}$ & $\mathrm{R} / \mathrm{R}^{*}$ & & & & \\
\hline \multirow[t]{10}{*}{$\mathrm{CW}$} & $-424 I A>T$ & 5'UTR & $214(306.2 \pm 32.5)$ & $180(315.3 \pm 33.1)$ & $34(321.7 \pm 36.4)$ & 0.005 & 0.025 & 0.025 & 0.025 \\
\hline & $-3 / 95 T>A$ & Intron I & $140(306.6 \pm 35.1)$ & $222(3 \mid 2.6 \pm 32.5)$ & $63(3 \mid 4.6 \pm 30.8)$ & 0.449 & I & 0.952 & I \\
\hline & $-6 / 8 T>A$ & Intron I & $217(311.9 \pm 30.9)$ & $183(310.6 \pm 36.3)$ & $27(309.9 \pm 34.7)$ & 0.859 & i & 0.995 & 0.859 \\
\hline & $+1 \mid 4 C>A$ & Intron2 & $199(314.2 \pm 34.5)$ & $186(308.8 \pm 31.9)$ & $39(309.5 \pm 35.7)$ & 0.496 & 1 & 0.952 & 1 \\
\hline & $+2042 A>G$ & Intron3 & $276(310.0 \pm 35.2)$ & $134(3 \mid 3.6 \pm 29.6)$ & $15(317.8 \pm 29.1)$ & 0.835 & I & 0.995 & I \\
\hline & $+2279 C>T$ & Intron3 & $206(308.7 \pm 32.4)$ & $184(3 \mid 3.3 \pm 32.8)$ & $35(316.9 \pm 40.9)$ & 0.815 & I & 0.995 & 1 \\
\hline & $h t l$ & . & $282(313.5 \pm 33.1)$ & $129(306.6 \pm 34.0)$ & $16(308.9 \pm 34.2)$ & 0.219 & 1 & 0.474 & 0.377 \\
\hline & $h t 2$ & . & $285(311.8 \pm 33.9)$ & $128(309.3 \pm 32.1)$ & $14(316.3 \pm 36.9)$ & 0.594 & I & 0.509 & 0.554 \\
\hline & ht4 & . & $330(312.5 \pm 32.5)$ & $90(307.3 \pm 37.3)$ & $7(302.4 \pm 20.1)$ & 0.174 & 0.931 & 0.474 & 0.59 \\
\hline & $h t 5$ & . & $332(311.2 \pm 34.0)$ & $93(311.6 \pm 32.0)$ & $2(299.5 \pm 29.0)$ & 0.340 & I & 0.474 & $0.40 \mathrm{I}$ \\
\hline \multirow[t]{10}{*}{ EMA } & $-424 I A>T$ & 5'UTR & $214(74.1 \pm 8.2)$ & $180(75.7 \pm 8.7)$ & $34(78.2 \pm 9.3)$ & 0.009 & 0.046 & 0.064 & 0.066 \\
\hline & $-3 / 95 T>A$ & Intron I & $140(75.2 \pm 7.6)$ & $222(75.0 \pm 8.9)$ & $63(75.6 \pm 9.6)$ & 0.583 & I & 0.991 & 1 \\
\hline & $-6 \mid 8 T>A$ & Intron I & $217(75.2 \pm 8.2)$ & $183(75.2 \pm 9.1)$ & $27(74.1 \pm 7.7)$ & 0.742 & 1 & 0.998 & 1 \\
\hline & $+114 C>A$ & Intron2 & $199(75.1 \pm 9.5)$ & $186(75.0 \pm 7.8)$ & $39(75.3 \pm 6.4)$ & 0.945 & 1 & 0.998 & 0.95 \\
\hline & $+2042 A>G$ & Intron3 & $276(75.1 \pm 8.5)$ & $\mid 34(75 . \mid \pm 8.9)$ & $15(76.8 \pm 9.0)$ & 0.799 & I & 0.998 & 1 \\
\hline & $+2279 C>T$ & Intron3 & $206(74.3 \pm 9.3)$ & $184(75.6 \pm 7.6)$ & $35(77.5 \pm 8.6)$ & 0.920 & 1 & 0.998 & 1 \\
\hline & $h t l$ & . & $282(75.2 \pm 8.8)$ & $129(75.0 \pm 8.3)$ & $16(76.1 \pm 5.9)$ & 0.716 & 1 & 0.713 & 0.671 \\
\hline & $h t 2$ & . & $285(75.6 \pm 8.2)$ & $128(74.3 \pm 9.1)$ & $14(74.3 \pm 9.9)$ & 0.402 & 1 & 0.574 & 0.486 \\
\hline & ht4 & . & $330(75.7 \pm 8.3)$ & $90(73.7 \pm 9.3)$ & $7(68.3 \pm 6.0)$ & 0.022 & 0.12 & 0.088 & 0.089 \\
\hline & $h t 5$ & . & $332(75.2 \pm 8.9)$ & $93(74.9 \pm 7.1)$ & $2(76.0 \pm 2.8)$ & 0.316 & I & 0.528 & 0.572 \\
\hline
\end{tabular}

Genotype and haplotype distributions, means, standard deviations (SD), $P$ values controlling for sire and age at slaughter as covariates was shown. $* \mathrm{C} / \mathrm{C}, \mathrm{C} / \mathrm{R}$, and R/R represent the common allele, heterozygotes and homozygotes for the rare allele, respectively. To achieve a simple correction for multiple testing of single-nucleotide polymorphisms (SNPs) in linkage disequilibrium (LD) with each other, the effective number of independent marker loci (5.35) in GHRH was calculated using the software SNPSPD [23], on the basis of the spectral decomposition (SpD) of matrices of pairwise LD between SNPs [24]. PCOR represents the simple corrected $P$ value. The permutation based $P$ values, $P W y$ were obtained by the Westfall and Young's method [25]. The FDR values $Q^{\text {SAM }}$ were estimated using the permutation test [26]. 


\section{Authors' contributions}

HS Cheong and HD Shin carried out the statistical analyses and drafted the manuscript. LY Kim, BL Park and YH Choi carried out the sequencing, SNP discovery and genotyping. DH Yoon, ER Chung and EW Park participated in the animal and phenotypic data collection. YM Cho participated in the design of the study. IC Cheong and SJ Oh participated in its design and coordination and helped to draft the manuscript. SG Yi and T Park carried out further statistical analyses. All authors read and approved the final manuscript.

\section{Acknowledgements}

This work was supported by a grant from BioGreen 2I Program, Rural Development Administration, Republic of Korea. The work of T Park was partially supported by the Natioanal Research Laboratory Program of Korea Science and Engineering Foundation.

\section{References}

I. Bauman DE: Bovine somatotropin: review of an emerging animal technology. J Dairy Sci I992, 75( I 2):3432-345 I

2. Sejrsen K, Foldager J, Sorensen MT, Akers RM, Bauman DE: Effect of exogenous bovine somatotropin on pubertal mammary development in heifers. J Dairy Sci 1986, 69(6): I528-I535.

3. Bass JJ, Oldham JM, Hodgkinson SC, Fowke PJ, Sauerwein H, Molan P, Breier BH, Gluckman PD: Influence of nutrition and bovine growth hormone (GH) on hepatic $\mathrm{GH}$ binding, insulin-like growth factor-I and growth of lambs. J Endocrinol I991, I28(2): $|8|-186$

4. Falaki M, Gengler N, Sneyers M, Prandi A, Massart S, Formigoni A, Burny A, Portetelle D, Renaville R: Relationships of polymorphisms for growth hormone and growth hormone receptor genes with milk production traits for Italian Holstein-Friesian bulls. J Dairy Sci 1996, 79(8): |446-|453.

5. Grochowska R, Sorensen P, Zwierzchowski L, Snochowski M, Loven dahl P: Genetic variation in stimulated $G H$ release and in IGFI of young dairy cattle and their associations with the leucine/ valine polymorphism in the GH gene. J Anim Sci 200I, 79(2):470-476.

6. Lagziel A, Lipkin E, Ezra E, Soller M, Weller Jl: An Mspl polymorphism at the bovine growth hormone (bGH) gene is linked to a locus affecting milk protein percentage. Anim Genet 1999 30(4):296-299.

7. Lin-Su K, Wajnrajch MP: Growth Hormone Releasing Hormone (GHRH) and the GHRH Receptor. Rev Endocr Metab Disord 2002, 3(4):313-323.

8. Moody DE, Pomp D, Barendse W: Rapid communication: restriction fragment length polymorphism in amplification products of the bovine growth hormone-releasing hormone gene. J Anim Sci 1995, 73( I 2):3789.

9. McDowell RS, Elias KA, Stanley MS, Burdick DJ, Burnier JP, Chan KS, Fairbrother WJ, Hammonds RG, Ingle GS, Jacobsen NE: Growth hormone secretagogues: characterization, efficacy, and minimal bioactive conformation. Proc Natl Acad Sci U S A 1995, 92(24): III65-III69.

10. Heffernan M, Summers RJ, Thorburn A, Ogru E, Gianello R, Jiang WJ, $\mathrm{Ng}$ FM: The effects of human $\mathrm{GH}$ and its lipolytic fragment (AOD9604) on lipid metabolism following chronic treatment in obese mice and beta(3)-AR knock-out mice. Endocrinology 200I, I 42( I 2):5 I 82-5 I89.

II. de Graaff LC, Mulder PG, Hokken-Koelega AC: Body proportions before and during growth hormone therapy in children with chronic renal failure. Pediatr Nephrol 2003, I 8(7):679-684.

12. Johannsson G, Bengtsson BA: Growth hormone and the acquisition of bone mass. Horm Res 1997, 48 Suppl 5:72-77.

13. Bonert VS, Elashoff JD, Barnett P, Melmed S: Body mass index determines evoked growth hormone $(\mathrm{GH})$ responsiveness in normal healthy male subjects: diagnostic caveat for adult GH deficiency. J Clin Endocrinol Metab 2004, 89(7):3397-340I.
14. Perras B, Schultes B, Schwaiger R, Metz C, Wesseler W, Born J, Fehm $\mathrm{HL}$ : Growth hormone-releasing hormone facilitates hypoglycemia-induced release of cortisol. Regul Pept 2002, I I 0(I):85-9|

15. Franco MM, Antunes RC, Silva HD, Goulart LR: Association of PIT I, GH and GHRH polymorphisms with performance and carcass traits in Landrace pigs. J Appl Genet 2005, 46(2): I 95-200.

16. Vance ML: Growth-hormone-releasing hormone. Clin Chem 1990, 36(3):415-420.

I7. Conklin D, Jonassen I, Aasland R, Taylor WR: Association of nucleotide patterns with gene function classes: application to human 3' untranslated sequences. Bioinformatics 2002 , I 8(I): 182-189.

18. APGS: Report of business for animal products grading. Animal products grading system, National Livestock Co-operatives Federation, Korea. 1995.

19. Primer and probe information. [http://www.snp-genetics.com/ reference/Supplementary information to GHRH.doc]

20. Vreeland WN, Meagher RJ, Barron AE: Multiplexed, highthroughput genotyping by single-base extension and endlabeled free-solution electrophoresis. Anal Chem 2002, 74( I 7):4328-4333.

21. Hedrick PW: Gametic disequilibrium measures: proceed with caution. Genetics 1987, I I7(2):331-34I.

22. Stephens M, Smith NJ, Donnelly P: A new statistical method for haplotype reconstruction from population data. Am J Hum Genet 200I, 68(4):978-989.

23. Nyholt DR: A simple correction for multiple testing for singlenucleotide polymorphisms in linkage disequilibrium with each other. Am J Hum Genet 2004, 74(4):765-769.

24. Nyholt DR: A simple correction for multiple testing for singlenucleotide polymorphisms in linkage disequilibrium with each other. Am J Hum Genet 2004, 74():765-769.

25. Westfall PH, Young SS, John Wiley \& Sons: Resampling-based multiple testing: examples and methods for $p$-value adjustment. 1993.

26. Benjamini $Y$, Hochberg $Y$ : Controlling the false discovery rate: a practical and powerful approach to multiple testing. JRSS series B 1995, 57:289-300.

Publish with Bio Med Central and every scientist can read your work free of charge

"BioMed Central will be the most significant development for disseminating the results of biomedical research in our lifetime. "

Sir Paul Nurse, Cancer Research UK

Your research papers will be:

- available free of charge to the entire biomedical community

- peer reviewed and published immediately upon acceptance

- cited in PubMed and archived on PubMed Central

- yours - you keep the copyright
BioMedcentral 